\title{
Developing Management Skills of Academic
}

Professionals

\section{By Len Ainsworth}

Texas Tech University

In the higher education setting, managers function in a variety of ways and with a variety of titles. While Vice Presidents for Finance or Academic Affairs are managers, so are deans and department chairpersons. Also, principal investigators, research team leaders, and graduate advisors perform specific management roles. Faculty members manage the time and efforts of large numbers of students in the learning process. The faculty also makes management decisions regarding curricula and professional and support personnel. A common thread in this variety of management roles is that the individuals involved are academic professionals. Much of what is called management training in other settings is missing in academia. Academic decision making traditionally depends upon the development of consensus of approaches among professionals, but typically few institutions have programs for developing needed skills.

At Texas Tech University, as in other institutions of higher education, we have a continuing turnover of academic professionals across the spectrum of positions with management responsibilities. Chairpersons, deans, advisors, etc. don't remain in their positions permanently. So, the development of consensus in decision making is complicated by changing players.

From To Improve the Academy: Resources for Student, Faculty, and Institutional Development, Vol. 7. Edited by J. Kurfiss, L. Hilsen, S. Kahn, M.D. Sorcinelli, and R. Tiberius. POD/New Forums Press, 1988. 


\section{Initiation}

An associate vice-president for research, with prior service as a department chairman and associate dean, first suggested the need for a program to assist in developing academic leaders. He invited me, his counterpart in academic affairs, to help in developing a program. The idea grew as needs for better academic managers were discussed. In the usual academic tradition we looked at needs and goals expressed in professional writings. Institutions in such diverse places as South Africa and Thailand (Kapp and Kaewsonthi, 1982) and, more recently, the United Kingdom (Sizer, 1987) have noted similar needs and aims. We accepted meeting the need for improved human relationships as a primary goal.

Next, we approached the president with an outling plan for organizing a program for development of academic management skills. With his approval we then invited individuals who represented several levels of management within the University to serve as an Advisory Board. That advisory board team quickly expanded itself to include members from the adjacent Health Sciences Center (HSC). The team discussed needs and began to set sub-goals as foci for training activities. As the goal setting discussions developed, the group expanded itself again to include members from the regional campuses of the HSC. Within a few weeks and a few meetings we had gone from a conversation between two administrators to a formal structure with an Advisory Board of over a dozen participants and a target group of over 200. The Advisory Board, at an early meeting, declared a working definition of the target group as all those in the institution with titles of principal investigator as well as chairpersons and those with administrative or supervisory responsibilities in the academic chain.

The Advisory Board accepted its primary responsibilities as identifying needs, setting goals, developing approaches and supporting the program. The continuing involvement of members of the advisory team was a factor in sustaining the program.

Early in the discussions of the Advisory Board, someone suggested naming the effort the Academic Leadership Development Program. The name, by its acronym ALDP, soon became a part of the institutional jargon. The board asked for financial support for materials and operations, and for a part-time coordinator. We submitted a proposal and the intergovernmental personnel act, throught the State of Texas, provided small funding assistance over a two year period; in addition, the management of the two institutions (University and HSC) funded some support for an additional year. More importantly, perhaps, the board developed (more accurately, evolved) a structure for program delivery. 
The Advisory Board of the ALDP reviewed a variety of approaches to leadership and management development, including commercially developed programs. For example, the Higher Education Management Institute (1978) materials developed through the American Council on Education which were applicable to some of the topics selected for study. There are many other training materials and many consultants for specific types of activities (such as time management) which would have addressed some of the needs. The Board rejected those approaches, however, in favor of increasing participation of local faculty. The depth of involvement of the advisory group was undoubtedly increased by the delivery system selected. The Board felt that active participation by a variety of people filling a variety of roles in the institution would motivate participants and help them internalize the management training.

Several faculty who had served as consultants to management made presentations to the Advisory Board. The Board decided that while representatives of management firms or consultants from other institutions would be used occasionally, their role was to be supplementary to the internal staff.

\section{Program Design}

The program was developed as a series of workshops. The Advisory Board sought to pursue the "balanced orientation between organizational process and outcome" noted by Whetten (1984). The Board discussed needs and named subgoals or topics for presentation. They also suggested learning objectives and possible instructors/developers for each topic or workshop. The two associate vice-presidents and the part-time coordinator served as an executive committee to facilitate the program. The executive group made agreements with the developers, usually campus faculty and administrators, for modules for the workshops. The developers held training sessions, when they considered it necessary, for those selected to conduct or assist with the activities. The developers/presenters were designated by the board as Leadership Associates. While one jokingly noted that the title and a half-dollar would get him a cup of coffee in the snack bar, the intent was to provide some recognition of individual efforts in the development program.

The Advisory Board assisted with publicizing each workshop. Generally, the developers and those trained as Associates conducted the workshop and obtained feedback from the participants for evaluation by the executive group. 


\section{Content}

Selection of the content and means of dealing with content illustrated participative approaches to management training. We surveyed academic administrators throughout the institutions, and the Advisory Board established priorities for the needs identified. We developed training activities in the area of goal setting, communication skills, performance appraisal, time management, planning, motivation, and program evaluation. Budgeting, staffing, and team building were also included. For some of the areas our intent was to develop consensus among practicing professionals; for others it was to provide information. For yet others, the primary effort was to help participants develop understanding of different approaches to dealing with particular issues.

The executive group and the advisory board spent little time in debating the relative importance of the areas selected for study. We selected them becasuse of the expressed interest of the vice-presidents, deans, department chairpersons and directors of major programs and research projects who would be the potential participants.

The Advisory Board discussed probable learning objectives for each major area, and asked faculty members in the area to be studied to recommend developers/facilitators. The Board then developed an agreement with the person chosen, for that individual to identify resources and materials needed, and to prepare an instructional module for workshop presentations. The developer selected others to assist, if necessary, and held a preliminary session with the Advisory Board. While the developer generally conducted the workshops the content was sometimes provided by others with particular skills. In a presentation of a decision-making model, for example, three faculty members alternated in presenting segments to small groups over a time period of several weeks.

The sessions on budgeting and staffing were handled as policy seminars with formal presentations and question-and-answer follow-up. Dayto-day problems, policy direction and projections for the future were treated. Strong participation in these sessions reflected interest in the what and why of institutional policies and procedures. The University's General Counsel spent an afternoon working with chairpersons on legal issues. The chairs came away impressed with the necessity for attention to detail and due process to avoid procedural entanglement.

All topics were addressed through problem solving activities and with participant involvement. Participants practiced on interdependent tasks and developed understanding of the neeed for independent work as well. Rather than being exhorted "to do your best," managers worked on processes to develop specific goal-setting. For some this resulted in bet- 
ter ways to organize a variety and mixture of objectives and tasks. For one chairman a complex task beccame even more complicated. The chairman initiated a redesign of his departmental structure, and before long had representatives from his dean's office, the graduate dean and the academic affairs office involved in his effort. This short term demand for greater time involvement of higher echelon administrators was a predictable aspect of the goal-setting content.

A few administrators attended almost every workshop (perhaps they paid more attention to the time management module than the rest of us). At the other extreme were those who attended only the first session, even though they had opportunity at that meeting to suggest both content and instructional approaches. Perhaps the latter group expected similar presidential invitations, lunch and visiting notables for the subsequent sessions as were provided for the kickoff activity. Some participants used the workshop content to initiate further discussions with faculty. At least one presenter, for example, was called upon to discuss performance evaluation with two different faculty groups after his workshop presentation to the audience of administrators.

\section{Results}

Presenters and participants said they liked the program design. The Leadership Associates, chosen from among those identified as having some expertise in the selected areas of study, readily accepted involvement in the programs. Advisory Board members, in most cases, maintained voluntary involvement over each year of their service. Each workshop drew a respectable volunteer audience. At least twenty percent of the identified population voluntarily participated in each workshop, although persons attending varied from activity to activity.

External support for materials, consultant help and small honoraria to Leadership Associates ended after the second year of the program. The management of the two institutions provided partial support for the coordinator for an additional year. The Advisory Board continued its activities and volunteer presenters continued to provide workshops throughout the third year of the program.

Institutions, like growing companies, are dynamic. Professional personnel come to the institution from many places, at different times, and with varied backgrounds. The ALDP provided new opportunities for interaction among those professionals. The chairpersons of department, for example, responded well to forums in which they could exchange ideas. Participants also reported positively to the opportunities for informal in- 
teraction provided through the program. Chairmen from across the institutions worked, im many cases for the first time, with administrators in other colleges and schools, on activities of broad interest.

The coordinator reported progress in development of managerial skills, based upon workshops participants' responses to survey instruments. Specific results on information aspects of the program were not assessed.

A specific area of the program related to performance appraisal and faculty evaluation. Since this directly and indirectly affects all academic managers, it is understandable that participants asked for the topics to be addressed again during the second year of the program. As senior managers (e.g., academic vice-presidents) change, the philosophies and criteria surrounding personnel evaluations may change, and managers at lower levels may need perception checks. ALDP workshops gave chairpersons opportunities to work with deans and vice-presidents in reviewing information and in development of approaches and guidelines for appraisal. Department chairpersons responded as favorably to this topic in the second year as in the first. The value of team-building and developing institutional climate reported in various literature seemed to be confirmed in this real world experience.

\section{Lessons Learned}

The experiences of academic administrators at Texas Tech University over a three year period lead to several conclusions. The ALDP experience indicates that (1) administrators are interested in improving themselves as managers; (2) participative approaches to planning are confirmed as valuable; and (3) participants value opportunities for interaction. Significant topics were repeated at participants' requests and almost as many participated in the reruns as in the original workshops.

Not all results were completely positive; for example, some of the workshops drew criticism for lack of either depth or applicability to many of the participants. Although significant numbers of managers requested particular topics in the initial survey, some of the topics did not attract large numbers of participants. Further study should be undertaken to determine whether conflicting activities, lack of timing or notification, type of topic, presenters or other factors caused the lack of involvement in those programs.

The goal of "professional development of the incumbents" (academic administrators) has long been supported by prestigious groups, including the National Commission on Higher Education (1978), while staff 
development programs continue to be stressed and models proposed (Lucas, 1986). The value of one approach to improved managerial skills through voluntary professional development and through participative planning has been confirmed in the program at Texas Tech University.

\section{References}

Higher Education Management Institute. (May, 1978). Handbook, Management Development and Training Program for Colleges and Universities. Coconut Grove, Florida: HEMI.

Kapp, C.A. and Kaewsonthi, Somkid. (1982). Second International Conference on Professional Development, Proceedings. Bangkok, Thailand.

Lucas, Ann F. (October, 1986). Academic Department Chair Training: The Why and the How of It. M.Suinicki, J. Kurfiss, J. Stone. To Improve the Academy, Vol. 5, (pp. 111-119). The Professional and Organizational Development Network in Higher Education.

National Commission on Higher Education Issues. (November, 1982). To Strengthen Quality in Higher Education, Washington, D,C.: American Council on Education.

Sizer, John. (January, 1987). Institutional Responses to Financial Reductions in the University Sector, Part 1: Report. Department of Education and Science (United Kingdom).

Whetten, David A. (November/December, 1984). Effective Administrators, Change, 16(6),(pp. 39-43). 